Canadian

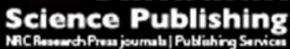

Applied Physiology, Nutrition, and Metabolism Physiologie appliquée, nutrition et métabolisme

\title{
Mechanical, Biochemical and Dietary Determinants of the Functional Model of Bone Development of the Radius in Children and Adolescents
}

\begin{tabular}{|r|l|}
\hline Journal: & Applied Physiology, Nutrition, and Metabolism \\
\hline Manuscript ID & apnm-2016-0666.R3 \\
\hline Manuscript Type: & Article \\
\hline Complete List of Authors: & $\begin{array}{l}\text { Ludwa, Izabella; Brock University, Department of Kinesiology } \\
\text { Falk, Bareket; Brock University, Department of Kinesiology } \\
\text { Ward, Wendy; Brock University, Department of Kinesiology } \\
\text { Gammage, Kimberley; Brock University, Department of Kinesiology } \\
\text { Klentrou, Panagiota; Brock University, Department of Kinesiology }\end{array}$ \\
\hline Keyword: & $\begin{array}{l}\text { muscle-bone unit, muscle strength, radius, bone speed of sound, bone } \\
\text { resorption }\end{array}$ \\
\hline \multicolumn{2}{|c}{} \\
\hline
\end{tabular}




\title{
Mechanical, Biochemical and Dietary Determinants of the Functional
}

\section{Model of Bone Development of the Radius in Children and}

\section{Adolescents}

Izabella A. Ludwa ${ }^{1}$, Bareket Falk ${ }^{1}$, Wendy E. Ward ${ }^{1}$, Kimberley L. Gammage ${ }^{1}$, Panagiota Klentrou ${ }^{1}$

${ }^{1}$ Department of Kinesiology, Brock University, St. Catharines, Ontario, Canada

Short Title: Functional Bone Development Model in Children

RUNNING HEAD: Determinants of Bone Development in Children

\author{
Corresponding author: \\ Panagiota (Nota) Klentrou, PhD \\ Professor \\ Department of Kinesiology \\ Brock University \\ 1812 Sir Isaac Brock Way \\ St. Catharines, ON \\ Canada L2S 3A1 \\ T $9056885550 \times 4538$ \\ F9059844851 \\ Email: nklentrou@brocku.ca
}




\begin{abstract}
This study examined the degree to which various mechanical, biochemical and dietary factors are related to non-weight bearing bone properties in 172 healthy peri-pubertal children $(11.7 \pm 2.0$ years). Dominant radial speed of sound (rSOS) was measured by transaxial quantitative ultrasound at distal radius. Potential modulating factors included somatic maturity offset (years from age of peak height velocity), grip strength, forearm lean cross-sectional area (CSA), physical activity, nutritional intake and amino-terminal cross-linking propeptide (NTx), reflecting bone resorption. In a hierarchical regression, grip strength adjusted for CSA was the second most important predictor of rSOS after the maturity offset $\left(\beta=0.22\right.$ and $\beta=0.33$, respectively; $\left.R^{2}=0.16\right)$. When relative grip strength was added to the model the contribution of sex was no longer significant. Calcium intake was a significant predictor of rSOS only after NTx was accounted for in the model $\left(\beta=0.17, \mathrm{R}^{2}=0.21\right)$. This may suggest that calcium's effects on the muscle-bone unit may be modulated through bone resorption. In the final model, relative grip strength together with maturity offset, dietary calcium and NTx explained up to $21 \%$ of the variance in rSOS in this cohort of children. Therefore, during the peri-pubertal stage, size-adjusted forearm muscle strength is related to radial bone strength after controlling for maturity, with calcium intake having a potential indirect association through NTx.
\end{abstract}

Keywords: muscle-bone unit, muscle strength, radius, bone speed of sound, bone resorption 


\section{INTRODUCTION}

To date, the majority of the research on bone growth and development in youth has focused on increasing the accrual of peak bone mass and reducing the risk of osteoporosis-related fractures later in life (Baxter-Jones et al. 2003, 2008; Cadogan et al. 1997; Valimaki et al. 1994; Wang et al. 2007). However, it has been suggested that the critical property for bone health is bone strength rather than bone mass (Rauch et al. 2004; Schöenau and Frost 2002). The Mechanostat Theory postulates that the development of bone strength occurs through appropriately applied mechanical loads placed on bone. During growth, some of the largest loads are applied by muscle contractions (Rauch et al. 2004; Schöenau and Frost 2002). The concept of a muscle-bone unit challenges the notion that bone mass should be related to age, but rather, that bone strength is a function of muscle strength (Schöenau and Fricke 2008). Examining bone strength from this perspective provides a functional model of bone development, which suggests that the muscular forces applied to bone lead to bone adaptation (Rauch and Schöenau 2001).

The timing and tempo of maturation varies amongst children and may not always coincide with chronological age. In fact, there are maturity-dependent changes associated with the functional model of bone development during growth. The peak rate of increase in muscle mass occurs after the peak rate of increase in height but before the peak accrual of bone mass and bone strength (Rauch et al. 2004). These changes in bone and muscle properties do not occur at the same chronological age, but tend to occur at the same maturational stage in boys and girls (Iuliano-Burns et al. 2001). As the temporal accrual of muscle mass and bone mass is related to the timing of peak height velocity, it is likely that the maturation process plays a role in the development of the functional muscle-bone unit. 
Various cross-sectional studies have demonstrated positive relationships between bone properties and muscle mass or force in youth (Janz et al. 2015; Macdonald et al. 2006; Schöenau et al. 2000, 2002; Wang et al. 2007; Wey et al. 2011). Other factors known to affect bone, such as physical (in)activity and nutrition, can help or hinder the muscle-bone unit relationship, with bone metabolism regulating the balance between bone accretion and deformation (Schöenau 2005a, 2005b). Previous studies have shown that appropriate daily calcium intake is important to enhancing bone mineral acquisition in girls (Cadogan et al. 1997; Valimaki et al. 1994). Habitual physical activity has also been shown to enhance both lean mass and bone accrual in youth (Baxter-Jones et al. 2003, 2008). Such systemic factors including hormones, biochemical markers, physical activity and diet can modulate the muscle-bone unit relationship by having both direct and indirect effects on muscle and bone that are not mutually exclusive (Rauch and Schöenau 2001).

Studies that examined the muscle-bone unit relationship often used measures of muscle and bone size (e.g., muscle cross-sectional area and bone mineral density or content) instead of strength. Pediatric studies using other techniques to measure bone or muscle strength, such as peripheral quantitative computed tomography (pQCT) or grip force respectively, are scarce and involved primarily clinical populations (Okumus et al. 2006; Schöenau et al. 1996; 2002;

Tenbrock et al. 2000). A few studies conducted in normal healthy children have demonstrated positive associations between grip strength and whole body bone mineral content (BMC) (GraciaMarco et al. 2011; Vicente-Rodríguez et al. 2008), upper arm BMC (Gracia-Marco et al. 2011) or calcaneal bone properties (Herrmann et al. 2015). Vicente-Rodriguez et al. (2008) found grip strength to be an independent predictor of whole body BMC. However, many of these studies did 
not take into account the aforementioned modulating factors that contribute to the functional model of bone development.

Quantitative ultrasound (QUS) can be used for the assessment of bone strength and is particularly suited for studies in healthy pediatric populations as it is portable, relatively inexpensive and non-invasive (no radiation exposure) (Njeh et al. 1999; Schoenau et al. 2004, Baroncelli 2008). Since it measures the speed of sound (SOS) along the bone it is not affected by bone size (Njeh et al. 1999), thus allowing for comparisons between children of different sizes (Baroncelli 2008; Foldes et al. 1995). QUS has demonstrated lower SOS values in children with fracture compared to healthy controls (Schalamon et al. 2004), and has been suggested as a useful method to assess bone quality and fracture risk in youth with bone and mineral disorders (Baroncelli et al. 2003). It has also been used, although to a limited extent, to demonstrate the effect of growth, body composition, dietary intake, and exercise training or physical activity on various bones (e.g. calcaneous, tibia, radius) and in different age groups of children and adolescents (Daly et al. 1997; Eliakim et al. 2001; Falk et al. 2000, 2003, 2008; Litmanovitz et al. 2003; Ludwa et al. 2010; Yao et al. 2011).

To appropriately assess the functional development of the muscle-bone unit, non-invasive measures of muscle strength relative to bone strength are needed, as well as measures of potential modulators. Therefore, the purpose of this study was to investigate the tenets of the functional model of bone development (Figure 1), as adapted from Rauch and Schöenau (2001), by examining the relationship between muscle characteristics (size and strength) and non-weight bearing bone properties, as reflected by the speed of sound at the radius (rSOS), in peri-pubertal boys and girls. Based on the functional model, biochemical components of bone, physical activity and nutritional factors were also examined to determine their systemic influence on the muscle- 
bone relationship. It was hypothesized that grip strength will be a positive determinant of rSOS, independent of maturity. Bone resorption and calcium intake, but not physical activity, will also be significant independent predictors of rSOS.

\section{MATERIALS AND METHODS}

\section{Participants}

A total of 178 children and adolescents, 8-16 years of age, were recruited from local school boards in the Niagara Region as well as through poster and information sessions at the University's recreation facility. Individuals with experiences affecting bone properties (i.e., use of steroid medication, growth delay, previous and/or current fracture) were excluded from the study. Girls with irregular menses or using oral contraceptives were also excluded. Specifically, two participants were excluded for being Type 1 diabetic, two were missing radial SOS measurements, and two participants had experienced a recent fracture. In the end, 172 children and adolescents ( 92 boys and 80 girls) met the inclusion criteria and agreed to participate in this study. This study and all related procedures received ethical clearance from the Brock University Research Ethics Board. Before testing, an informed consent form was signed by the parent or legal guardian and the participant.

\section{Anthropometry and Maturity}

Standing and sitting height were measured using a stadiometer (Ellard Instrumentation, Monroe, WA, USA) mounted to the wall and recorded to the nearest $0.1 \mathrm{~cm}$. Leg length was calculated by subtracting seated height (height minus sitting height) from standing height. Body mass was measured to the nearest $0.1 \mathrm{~kg}$ using a calibrated balance beam scale (Zenith Digital Scale). Skinfold thickness was measured in triplicate at two sites (triceps and subscapular) using 
Harpenden calipers (British Indicators, Herts, England), and the median was recorded. Adiposity (percent body fat) was estimated from the sum of these skinfolds, using age- and maturity-specific equations, as previously described (Slaughter et al. 1988). All measurements were performed by the same investigator to avoid inter-observer variability (ICC $=0.996)$.

The somatic maturity offset (years from peak height velocity) was estimated using sex specific regression equations (Mirwald et al. 2002). Age of peak height velocity (PHV) is one of the most commonly used methods of assessing somatic maturity in adolescents (Malina et al. 2004; Mirwald et al. 2002). The determination of the age of PHV requires serial measurements of growth over a number of years to ascertain peak height velocity, and thus, can only be determined retrospectively from longitudinal data. Mirwald et al. (2002) developed a simple, non-invasive method of assessing somatic maturity in children using known differential growth rate in height, sitting height and leg length. The changing ratio of leg length to sitting height was used to create a sex-specific equation to estimate maturity offset, the years from the age of $\mathrm{PHV}$, using single rather than serial measurements with a standard error of estimate 0.49 years for boys and 0.50 years for girls (Mirwald et al. 2002). Female participants were also asked to indicate their menstrual status including age at menarche (if reached) and frequency of menses in days (see exclusion criteria above). These variables were used for inclusion purposes but were not used in the analysis.

\section{Muscle Size and Strength}

Cross-sectional area (CSA, muscle plus bone) was estimated at $65 \%$ of dominant forearm length using a simplified anthropometric method (Margonato et al. 1994). Forearm length was measured to the nearest $0.1 \mathrm{~cm}$ as the distance between the ulnar styloid process and the olecranon using an anthropometric tape measure. The circumference at $65 \%$ forearm length represents the maximal 
circumference of the forearm and was used to derive the radius with $\mathrm{R} 1=\mathrm{C} / 2 \pi$. The radius of the limb (muscle and bone) was then calculated from the difference of R1-R2, where R2 is the mean of the forearm anterior and posterior skinfold thickness. Skinfold thickness was measured in triplicate using Harpenden calipers (British Indicators, Herts, England) and the median value at each site was recorded. This newly calculated radius was then used to calculate muscle-plus-bone using the standard formula of $\pi r^{2}$.

Maximal dominant forearm strength was assessed by a hand-held dynamometer to determine maximal isometric grip force. The device handle was adjusted to the participant's grip size and the test performed with the participant in a standing position with their dominant arm abducted at 45 degrees, with the elbow extended (Lorbergs et al. 2011). Participants were instructed to squeeze the instrument as hard as possible for three seconds. Measurements were recorded to the nearest $0.5 \mathrm{~kg}$. The participant's largest value (best trial) was used to represent their maximal isometric grip force.

\section{Bone Properties and Resorption}

Transaxial quantitative ultrasound (Sunlight Omnisense ${ }^{\text {TM }} 7000$ S, Sunlight Medical, Israel) was used to assess bone properties by measuring the speed of sound $(\mathrm{m} / \mathrm{s})$ along the bone at the distal $1 / 3$ of the radius (rSOS). The radius was specifically chosen to separate the influence of muscle properties on bone strength from those of weight-bearing or ground reaction forces (Greene et al. 2005; Macdonald et al. 2006). The area of measurement for the radius was the midpoint between the olecranon process and the tip of the third phalanx. Wide scans of 140 degrees around the radius were performed. All measurements consisted of at least three consistent cycles. A system quality verification of the QUS was performed with a Perspex phantom before the first test of each day. The intra-operator coefficient of variation of the QUS measurements in 10 children was 
$21 \%$ and the interclass correlation coefficient was 0.98 . SOS has been shown to predict fractures independent of bone mineral density (BMD), suggesting that it is measuring an aspect of bone strength (Nguyen et al. 2004). Indeed, QUS measurements are related to bone density, elasticity and microstructure (Gluer et al. 1994), but not to cortical thickness (Njeh et al. 1999). QUS has been previously used to demonstrate the effect of exercise training or physical activity on various bones (e.g., tibia) and in different age groups including children (Daly et al. 1997; Falk et al. 2003, 2007, 2010; Holmes et al. 2010).

Cross-linked N-telopeptides of bone type I collagen (NTx) was measured from first morning mid-stream urine samples and analyzed using enzyme-linked immunosorbent assay (ELISA) kits (Osteomark ${ }^{\circledR}$ NTx Urine Assay, Alere Scarborough, Inc., USA). All samples were analyzed in duplicate with the mean of the duplicate absorbancies used to determine NTx concentrations. All assayed plates were read using the same microplate reader and absorbencies analyzed using GraphPad Prism (GraphPad Software, Inc., USA). Urinary creatinine was analyzed in duplicate using a creatinine colormetric assay kit (MicroVue ${ }^{\mathrm{TM}}$, Quidel Corporation, SanDiego, CA, USA) based on a modified Jaffe method. NTx values were corrected for urinary creatinine and final results reported as nmol BCE/mmol creatinine. The intra-assay and inter-assay coefficient of variation for NTx was, $2.5 \%$ and $11.6 \%$, respectively.

\section{Physical Activity and Dietary Intake}

Physical activity was assessed using Actigraph GT1M accelerometers. The accelerometers were programmed to record activity counts at 5-second epochs along the vertical axis to measure accelerations from 0.05-2 G's at a frequency of 0.25-2.5 Hz. Participants were instructed to wear the belted accelerometer for 7 consecutive days, against the skin, on the right hip for all waking hours. Physical activity $\log$ s were used to record times the accelerometer was removed (i.e., 
during bathing, swimming, competition). A minimum of three weekdays and one weekend day, with a minimum of 10 hours of waking data recorded, were used for analysis (Penpraze et al. 2006). Based on previously established cut-off values (Trost et al. 2001, 2002) the total combined time spent in moderate, hard, and very hard types of activities (MVH) was used to quantify daily physical activity.

Dietary intake was evaluated using a 24-hour recall interview as previously described (Moore et al. 2007). The 24-hour recall method is the most commonly used assessment tool in large cross-sectional surveys and skeletal development studies in both children and adults (Moore et al. 2007). This method has numerous advantages including responsiveness to change in food supply and habit (Guenther et al. 1997; Harrison et al. 2000). In brief, participants were asked to recall everything consumed (including foods, beverages, sauces and condiments) the day prior to the interview. Prior to answering the 24-hour dietary recall, participants were asked if the last 24 hours were typical for their diet. If it were not a typical day (e.g. birthday party, family gathering, eating out), they reported two days prior to the interview date. The recall started from the first meal or beverage consumed at waking until midnight of the reporting day. Pictures representing different portion sizes of foods, sizes and measurements of various kitchenware models were used to help ascertain the most accurate amount of food that was consumed. Dietary analysis was conducted (using Nutritionist Pro ${ }^{\mathrm{TM}}$, Axxya Systems, USA) to estimate total energy intake (kcal), as well as protein $(\mathrm{g})$, calcium $(\mathrm{mg})$ and vitamin $\mathrm{D}(\mu \mathrm{g})$ intake.

\section{Statistical Analysis}

Sex-specific descriptive statistics were determined for all study variables by calculating the mean and standard deviation (SD). Skewness and kurtosis were used to assess the assumption of normality for each variable and all were found to be within an acceptable range $(-2$ to +2$)$. Note 
that there were a total of 36 missing values across all variables. These missing values were accounted for using the group's mean value for that particular time point. All 172 participants had complete data for rSOS, anthropometric and maturation measurements, and all nutritional components. However, few participants did not attend all testing sessions resulting in 7 missing grip strength measurements. There were also a total of 25 physical activity measurements missing due to participants not wearing the accelerometers correctly, thus resulting in an incorrect record of wear time. In addition, 4 NTx data points were missing due to participants not providing a urine sample.

Independent sample t-tests were performed to determine differences in participant characteristics, muscle-bone unit and modulator (physical activity and nutrition) variables between boys and girls. Pearson correlations were used to identify relationships between rSOS, muscle strength and size, MVH physical activity, nutritional intake and NTx. The strength of the relationship noted in bivariate correlations was used to help select predictor variables for the regression models. Hierarchical regression was used to evaluate the contribution of muscle and behavioural variables to dominant radial SOS, with variables entered in blocks in the following order: (1) sex and maturity offset, (2) grip strength, (3) physical activity and dietary calcium, and (4) NTx. Due to the collinearity between age and maturity offset these two variables were examined in the regression analysis separately. In order to be in line with previous studies (e.g. Macdonald et al. 2006), we report the regression results using maturity offset only. However, when the analysis was done with age instead of maturity offset the results were very similar. The only dietary variable used in the analysis was calcium as it had the strongest correlation with rSOS. The other nutritional variables were excluded from the final model as their inclusion actually decreased the total amount of variance that could be explained. 
Variables were entered in this particular order to help reveal the most appropriate predictors of bone strength from our adapted functional model of bone development (Figure 1), based on Rauch and Schöenau (2001). This order was also used to see if our results using QUS supported findings previously reported by Dual-Energy X-ray Absorptiometry (DXA) and pQCT. The use of NTx as the final variable in the model was used to determine whether its addition helped to further explain the functional model of bone development. Statistical analyses were performed using IBM SPSS Statistics version 21 for Windows (IBM Corp., Armonk, NY). A twosided alpha level of 0.05 was the criterion for significance for all statistical analyses.

\section{RESULTS}

Values for physical characteristics of boys and girls appear in Table 1, with muscle-bone unit and modulator variables presented in Table 2. Boys and girls were similar in age, height, weight, and lean body mass. Girls were more mature than boys and had higher percent body fat $(p<0.001)$.

There were no statistical differences between boys and girls in rSOS or bone resorption (NTx). Although girls appear to be less active than boys, this difference in MVH activity was not statistically significant $(p=0.07)$. Boys had greater muscle size and absolute grip strength than girls $(p<0.05)$ but these differences in grip strength disappeared when adjusted for muscle-andbone size (CSA). There were also sex differences in dietary intake, with boys having a greater total energy, protein and calcium intake than girls $(p<0.05)$. After adjusting for body mass, however, only total energy intake $(p=0.03)$ was higher in boys.

We observed significant positive correlations between rSOS and maturity offset, muscle strength, muscle size, physical activity, and NTx $(r=0.22-0.36, p<0.01)$. Grip strength was found to have a slightly greater positive association with rSOS than forearm muscle size, even after adjusting for muscle CSA ( $\mathrm{r}=027-0.30$ vs. $0.22, \mathrm{p}<0.01$ ). There were no significant correlations 
between rSOS and dietary intake. However, all dietary variables including total energy, protein, vitamin $\mathrm{D}$ and calcium intake relative to body mass were associated with $\mathrm{NTx}(\mathrm{r}=0.21-0.23$, $\mathrm{p}<0.01)$.

Absolute grip strength did not enter as a significant predictor of rSOS in the regression models. However, in model 2, relative grip strength was the second most important predictor of rSOS after maturity offset, and alone could explain an additional $4 \%$ of the variance in rSOS over and beyond the $12 \%$ explained by the maturity offset and sex in model 1 . In addition, once relative grip strength was entered into the model, the contribution of sex was no longer significant in the model (Table 3). MVH physical activity was not a significant predictor of rSOS. In the final model, maturity offset, relative grip strength, dietary calcium and NTx were found to be the only significant predictors of rSOS, accounting for $21 \%$ of the variability in rSOS (Table 3).

\section{DISCUSSION}

The main purpose of this study was to investigate the functional model of bone development proposed by Rauch and Schöenau (2001) by examining the primary mechanical challenges (i.e. muscle force) to bone strength during growth, along with behavioural factors (i.e., physical activity and nutrition). This was the first study to include an indicator of bone resorption in the investigation of the muscle-bone unit in youth, in addition to combining non-invasive measures of strength for both muscle and bone. Maturity, relative grip strength, dietary calcium intake and NTx accounted for $21 \%$ of the variance in rSOS in children 8-16 years of age. Figure 2 presents the adapted functional model of bone development supported by our results. Overall, we have shown that relative grip strength is related to radial bone strength, even after controlling for sex and maturity. Furthermore, the addition of an index of bone resorption (NTx) to our model contributed significantly to the observed variance in radial bone strength, which helped to further 
explain the functional model of bone development. Calcium intake was a significant predictor of rSOS only after adding NTx to the regression model, which suggests that the effect of calcium intake on the muscle-bone unit may be modulated through bone resorption. Likewise, all dietary variables including total energy, protein and vitamin D intake were correlated with NTx.

As previously mentioned, there are maturity-dependent changes associated with the functional model of bone development during growth. The functional model of bone development is complex. One of the novelties of this study was the examination of multiple predictors to explain rSOS. It is not always clear what is the best way to account for the influence of maturity within the model, due to the indirect effect that maturity can have on each determinant of bone strength. The important role of maturation on rSOS and its determinants is observed by maturity having the greatest contribution to $\operatorname{rSOS}(12 \%)$, compared with all other predictors.

Relative grip strength was found to account for an additional $4 \%$ in rSOS over and beyond maturity and sex. In fact, with relative grip strength in the model, the contribution of sex was no longer significant. The absence of an effect of sex on distal radius bone strength after accounting for forearm muscle size is also consistent with the pQCT-derived compression strength (BSI) findings of Frank et al. (2010). This is in line with the functional model of bone development which postulates that the primary mechanical challenges to bone's mechanostat during growth stem from increases in bone length and muscle force (Frost 1987; Rauch and Schöenau 2001). However, the amount of variance in rSOS explained by our model (21\%) was still less than what is typically reported in the literature. In adults, Frank and colleagues (2010) demonstrated that isokinetic grip force, muscle CSA, arm length, and sex explained $79-80 \%$ of the variance of pQCT-derived torsional strength (SSI) at the radial diaphysis. Furthermore, Lorbergs et al. (2011) found that grip strength alone accounted for $21 \%$ of SSI at the proximal radius in men and $23 \%$ of 
compression strength (BSI) at the distal radius in women. In children and young adults, aged 6-22 years, muscle size, as a surrogate for strength, accounted for $77 \%$ of cortical area at the proximal radius (Schöenau et al. 2000). Our significant positive associations between muscle force, muscle size and radial SOS are also comparatively weaker than those in the pediatric literature between various bone and muscle measurements at the radius ( $r=0.22-30$ vs. $r=0.85-95$, respectively) (Schöenau 2005b; Schöenau et al. 1996, 2001; 2002; Tenbrock et al. 2000; Wey et al. 2011), humerus ( $\mathrm{r}=0.54-0.81)$ (Daly et al. 2004; Wang et al. 2007), and at the tibia ( $\mathrm{r}=0.54-77)$ (Janz et al. 2015; Macdonald et al. 2006). This discrepancy in the strength of the relationships may be due to differences in bone outcomes (SOS vs. BMD or BMC, SSI or BSI), or differences in the site of bone assessment (e.g., distal radius, which is trabecular bone versus mid-radius, which is cortical bone).

These differences can in part be due to how bone outcomes are theoretically determined to estimate bone strength. The skeletal characteristics that contribute to bone strength include the quantity and quality of bone. BMD and BMC represent the quantity of bone material. Specifically, this DXA-derived bone mineral assessment uses a 2-dimensional technique to quantify bone, which is problematic in youth as it does not accurately account for differences in bone size (Bachrach 2005). The quality of material refers to the condition of the material and how it is distributed, its geometry (Ammann and Rizzoli 2003; Klentrou 2016; Turner and Robling 2004). SSI and BSI are bone outcomes derived from geometric and material bone properties measured by pQCT. These parameters of bone geometry, bone volume, CSA and cortical thickness have been shown to be positively related to each other, and can also account for up to $80 \%$ of the variance in bone strength (Voide et al. 2008). This may explain the larger observed associations between muscle and bone properties using pQCT as opposed to QUS. Like DXA and pQCT, QUS is not a 
direct measure of bone strength, but contrary to DXA, the SOS score takes into account both the qualitative and quantitative aspects that make up bone strength (Foldes et al. 1995). Perhaps its lack of specificity contributes to weaker correlations between muscle and bone properties, compared with pQCT. Moreover, QUS measures the SOS distally to the muscular region in the forearm generating the force. It is possible the weaker relationship between muscle and bone strength may be from the dissociation between the measurement sites of these two outcomes.

Unlike bone strength, direct measures of muscle strength are possible. However, many studies have used muscle size measures such as muscle CSA as surrogate measures for muscle strength. This approach is based on the fact that muscle strength generally scales with muscle size and assumes appropriate measures of size are sufficient for muscle-bone unit investigations (Petit et al. 2005). A number of studies have demonstrated muscle strength and power to be similarly predictive of bone strength as muscle size (Frank et al. 2010; Lorbergs et al. 2011; Macdonald et al. 2006), which is in contrast to our findings that grip strength was a stronger determinant of radial SOS than muscle CSA. Beyond muscle CSA, neuromuscular properties may help to account for increases in muscle strength and function with growth and maturation (Blimkie 1989), and could explain why relative grip strength and not absolute grip strength was a significant predictor of radial SOS in our regression models. Taking direct measures of muscle strength are advantageous as muscle size is only one component that contributes to overall muscle strength, particularly during maturation.

The advantage of using somatic maturity (years from the age of peak height velocity) in our assessment of the muscle-bone unit is that it allowed us to combine both sexes during analysis to potentially capture variations in bone determinants that occur at similar maturity levels in boys and girls. During maturation there are changes in the size of both muscle and bone, which would 
have direct implications to their strength measurements. Vicente-Rodriguez et al. (2008) found that the association between grip strength and whole body BMC in adolescents disappeared after controlling for lean mass. This may indicate that the relationship between bone and muscle strength may be mediated by lean mass and highlights the importance of body size considerations when assessing the muscle-bone unit in growing youth. Moreover, the changes in physical activity levels and dietary habits associated with maturation can indirectly affect rSOS. During adolescence, particularly in girls, activity levels decline (Sallis 2000; Sherar et al. 2007; Trost et al. 2002), and the consumption of dairy products is insufficient (Fiorito et al. 2006). Separate regressions to examine sex-specific determinants of rSOS were not conducted because the contribution of sex to the model failed to remain significant after relative grip strength was added. It is possible the individual sample sizes for boys and girls were insufficient to allow for observed differences in various predictors of rSOS. Also, it is likely that any potential sex-specific differences were masked by the much larger and significant contribution of maturity.

The contribution of physical activity in the regression models for rSOS was not significant. This is similar to Cvijetic et al. (2003) who also found physical activity was not associated with ultrasonic measurements of calcaneal bone stiffness in children and adolescents. Conversely, other studies have demonstrated positive associations between physical activity levels and QUS measurements (De Smet et al. 2015; Prais et al. 2008). Therefore, the influence of physical activity on the muscle-bone unit relationship is ambiguous within the literature and depends on how physical activity is measured, and the type, location, and indices of bone being investigated. We measured MVH physical activity using accelerometers along the vertical axis, which made our physical activity measures sensitive to weight-bearing types of activity. Since the radius is a non-weight bearing bone, it is not surprising that physical activity did not enter as a 
significant predictor of rSOS in our model. It is possible that the uniaxial measurement underestimated physical activity levels and the use of a triaxial monitor would have captured a broader range of activities that may have had an influence on radial bone strength.

Adequate nutrition is important for both muscle and bone development. Total dietary protein, calcium and vitamin D intake are key nutritional factors that may act directly or indirectly on muscle and bone (Bass et al. 2005a). However, in our study none of these variables were correlated with radial SOS and did not enter in the overall model as significant predictors of radial SOS. Muscle and bone are negatively impacted when there is nutritional deficiency, specifically when there is protein and energy deficiency (Bass et al. 2005a, 2005b). Our participants were healthy, typically-developing children without signs of protein and energy deficits. Therefore, it is not surprising that such variables did not enter in the regression models as significant predictors of radial SOS.

The central piece of bone regulation in the functional model of bone development is the regulatory feedback loop between bone deformation (tissue strain) and bone formation, which is controlled by osteoblasts and osteoclasts (Rauch and Schöenau 2001). The majority of studies use imaging technologies to examine bone geometry and cite changes in periosteal or endocortical bone surfaces to infer the balance between bone formation and deformation (Daly et al. 2004; Macdonald et al. 2006; Schöenau et al. 2000). This is the first study to measure a marker of bone resorption within the context of the functional model of bone development in healthy children. When NTx was included in the regression analysis, we found it helped to explain an additional $3 \%$ of variance in radial SOS. Measuring markers of both bone formation and resorption may help to elucidate their individual contributions to the development of the functional muscle-bone unit, and potential mediating pathways for other bone strength determinants. 
In the present study, we did find dietary calcium to be a weak but significant predictor of radial SOS but it only became a significant determinant of radial SOS after NTx was entered into the regression model. This suggests that the effects of calcium intake on the muscle-bone unit may be modulated through bone resorption. Calcium is a major constituent of bone and dietary calcium is thought to be an important determinant in maximizing bone mineral acquisition during growth (Bass et al. 2005a; Cadogan et al. 1997; Valimaki et al. 1994). Nutritional intake acts indirectly through endocrine factors on bone metabolism (modeling and remodeling) (Bass et al. 2005a), which may explain the observed correlation between NTx and calcium intake, as well as the significant correlations of NTx with the relative energy, protein and vitamin D intakes. Additional studies using bone formation and other markers of bone metabolism, along with hormonal factors (particularly estrogen and IGF-1), are needed to clarify the relationship of dietary calcium and other nutritional components with the muscle-bone unit during growth.

As we were trying to assess the functional model of bone development, any missing component from this model could be considered a limitation to our study. For example, we did not assess hormonal levels and, due to the collection of only urine samples, markers of bone formation were not measured. It could also be argued that QUS does not present discrete information on bone content, size, geometry or strength, but the SOS score reflects both qualitative and quantitative properties of bone that contribute to bone strength (Baroncelli 2008). Importantly, transaxial QUS provides us with a measure reflecting bone strength that is independent of bone size, which is particularly important when investigating growing children.

Despite these limitations, ours is the first study of the functional model of bone development in a cohort of healthy children to include both measures of muscle and bone strength (rather than size), along with various modulators. An important strength of our study is that our 
measures of muscle and bone strength (relative grip strength and rSOS) are size-independent. Therefore, size is not a confounding factor in our muscle-bone interactions, which reiterates that muscle strength is a primary contributor to the development of radial bone strength. Another strength of our study was the examination of markers of bone metabolism, albeit only resorption. Finally, being able to identify these relationships and support previous findings by DXA or pQCT demonstrates that using QUS along with grip strength can be used to examine the functional model of bone development at the radius. Evaluating bone health from the perspective of a functional muscle-bone unit may increase the sensitivity of fracture prediction at the distal radius, which is a common fracture site in youth (Khosla et al. 2003).

In conclusion, this study found that among 8-16years old children and adolescents, after controlling for sex and maturity, relative grip strength is related to radial SOS (reflecting bone strength). Dietary calcium was a weak but significant contributor of rSOS and may be modulated through bone resorption. Longitudinal studies measuring both muscle and bone strength are also needed to determine how the functional muscle-bone unit adapts with respect to changes in its modulators as a result of growth and maturation.

\section{Conflict of Interest Statement}

The authors declare that there are no conflicts of interest associated with this manuscript.

\section{ACKNOWLEDGEMENTS}

We would like to thank the participants and their parents for taking the time to be involved in this study. In addition, we appreciate the help of all the undergraduate and graduate students involved in this project, specifically Elisabeth Wiens. This research was funded by the Canadian Institutes 
of Health Research (CIHR \#199944). I.A. Ludwa was supported by the Ontario Graduate Scholarship (OGS) and the Ontario Graduate Scholarship in Science and Technology (OGSST).

W. Ward holds a Canada Research Chair (Tier 2) in Bone and Muscle Development. 


\section{REFERENCES}

Ammann, P., and Rizzoli, R. 2003. Bone strength and its determinants. Osteoporosis. Int.14(Suppl 3): S13-18. doi:10.1007/s00198-002-1345-4. PMID:12730800.

Bachrach, L.K. 2005. Osteoporosis and measurement of bone mass in children and adolescents. Endocrinol. Metab. Clin. North. Am. 34(3): 521-535. doi:10.1016/j.ecl.2005.04.001.

PMID:16085157

Baroncelli, G.I. 2008. Quantitative ultrasound methods to assess bone mineral status in children: technical characteristics, performance, and clinical application. Pediatr. Res. 63: 220-228. doi:10.1203/PDR.0b013e318163a286. PMID:18287958.

Baroncelli. G.I., Federico, G., Bertelloni, S., Sodini, F., De Terlizzi, F., Cadossi, R., and Saggese, G. 2003. Assessment of bone quality by quantitative ultrasound of proximal phalanges of the hand and fracture rate in children and adolescents with bone and mineral disorders. Pediatr. Res. 54(1): 125-136. doi:10.1203/01.PDR.0000069845.27657.EB. PMID:12700367.

Bass, S.L., Eser, P., and Daly, R. 2005a. The effect of exercise and nutrition on the mechanostat. J. Musculoskel. Neur. Interact. 5(3): 239-254. PMID:16172515.

Bass, S., Saxon, L., Corral, A.M., Rodda, C., Strauss, B., Reidpath, D., and Clarke, C. 2005 b. Near normalisation of lumbar spine bone density in young women recovered from adolescent onset anorexia nervosa: a longitudinal study. J. Pediatr. Endocrinol. Metab. 18(9): 897-907. PMID:16279368.

Baxter-Jones, A.D., Eisenmann, J.C., Mirwald, R.L., Faulkner, R.A., and Bailey, D.A. 2008. The influence of physical activity on lean mass accrual during adolescence: a longitudinal analysis. J. Appl. Physiol. 105: 734-741. doi:10.1152/japplphysiol.00869.2007. PMID:18467546

Baxter-Jones, A.D., Mirwald, R.L., McKay, H.A., and Bailey, D.A. 2003. A longitudinal analysis of sex differences in bone mineral accrual in healthy 8-19-year-old boys and girls. Ann. Hum. Biol. 30: 160-175. PMID:12637192.

Blimkie, C.J. 1989. Age- and sex-associated variation in strength during childhood:

Anthropometric, morphologic, neurologic, biomechanical, endocrinologic, genetic, and physical activity correlates. In Perspectives in Exercise Science and Sports Medicine, Vol. 2: Youth, Exercise and Sports. Edited by C.V. Gisolfi. Benchmark Press, Indianapolis, IN. pp. 99-163.

Cadogan, J., Eastell, R., Jones, N., and Barker, M. 1997. Milk intake and bone mineral acquisition in adolescent girls: randomized, controlled intervention trial. Br. Med. J. 315: 1255-1260. PMID:9390050. PMCID:PMC2127785.

Cvijetic, S., Baric, I.C., Bolanca, S., Juresa, V., and Ozegovic, D.D. 2003. Ultrasound bone measurement in children and adolescents. Correlation with nutrition, puberty, anthropometry, and physical activity. J. Clin. Epidemiol. 56(6):591-597. PMID:12873655. 
Daly, R.M., Rich, P.A., and Klein, R. 1997. Influence of high impact loading on ultrasound bone measurements in children: a cross-sectional report. Calcif. Tissue Int. 60: 401-404. PMID:9115154.

Daly, R.M., Saxon, L., Turner, C.H., Robling, A.G., and Bass, S.L. 2004. The relationship between muscle size and bone geometry during growth and in response to exercise. Bone 34: 281287. doi:10.1016/j.bone.2003.11.009. PMID:14962806.

De Smet, S., Michels, N., Polfliet, C., D'Haese, S., Roggen, I., De Henauw, S., and Sioen, I. 2015. The influence of dairy consumption and physical activity on ultrasound bone measurements in Flemish children. J. Bone. Miner. Metab. 33(2):192-200. doi:10.1007/s00774-014-0577-7. PMID:24633491.

Eliakim, A., Nemet, D., and Wolach, B. 2001. Quantitative ultrasound measurements of bone strength in obese children and adolescents. J. Pediatr. Endocrinol. Metab. 14:159-164. PMID:11305793.

Falk, B., Braid, S., Moore, M., O'Leary, D., Sullivan, P., and Klentrou, P. 2008. Bone properties in overweight pre- and early-pubertal boys. Pediatr. Exerc. Sci. 20: 50-61. PMID:18364534.

Falk, B., Braid, S., Moore, M., Yao, M., Sullivan, P., and Klentrou, P. 2010. Bone properties in child and adolescent male hockey and soccer players. J. Sci. Med. Sport 13(4): 387-391. doi:10.1016/j.jsams.2009.03.011. PMID:19574094.

Falk, B., Bronshtein, Z., Ziegel, L., Constantini, N.A., and Eliakim, A. 2003. Quantitative ultrasound of the tibia and radius in prepubertal and early-pubertal female athletes. Arch. Pediatr. Adolesc. Med. 157: 139-143. PMID:12580682.

Falk, B., Galili, Y., Zigel, L., Constantini, N., and Eliakim, A. 2007. A cumulative effect of physical training on bone strength in males. Int. J. Sports Med. 28: 449-455. doi:10.1055/s-2006924517. PMID:17111316.

Falk, B., Sadres, E., Constantinin, N., Eliakim, A., Zigel, L., and Foldes, A.J. 2000. Quantitative ultrasound (QUS) of the tibia: a sensitive tool for the detection of bone changes in growing boys. J. Pediatr. Endocrinol. Metab. 13:1129-1135. PMID:11085192.

Foldes, A.J., Rimon, A., Keinan, D.D., and Popovtzer, M.M. 1995. Quantitative ultrasound of the tibia: a novel approach for assessment of bone status. Bone. 17: 363-367. PMID:8573409.

Fiorito, L.M., Mitchell, D.C., Smiciklas-Wright, H., and Birch, L.L. 2006. Dairy and dairy-related nutrient intake during middle childhood. J. Am. Diet. Assoc. 106(4): 534-542. doi:10.1016/j.jada.2006.01.005. PMID:16567149. PMCID:PMC2531148. 
Frank, A.W., Lorbergs, A.L., Chilibeck, P.D., Farthing, J.P., and Kontulainen, S.A. 2010. Muscle cross sectional area and grip torque contraction types are similarly related to pQCT derived bone strength indices in the radii of older healthy adults. J. Musculoskel. Neur. Interact. 10(2): 136-141. PMID:20516630.

Frost, H.M. 1987. Bone "mass" and the "mechanostat": a proposal. Anatomical Record 219: 1-9. doi:10.1002/ar.1092190104. PMID:3688455.

Gracia-Marco, L., Vicente-Rodríguez, G., Casajús, J.A., Molnar, D., Castillo, M.J., and Moreno, L.A. 2011. Effect of fitness and physical activity on bone mass in adolescents: the HELENA Study. Eur. J. Appl. Physiol. 111(11): 2671-2680. doi:10.1007/s00421-011-1897-0. PMID:21394637.

Gluer, C.C., Wu, C.Y., Jergas, M., Goldstein, S.A., and Genant, H.K. 1994. Three quantitative ultrasound parameters reflect bone structure. Calcif. Tissue Int. 55: 46-52. PMID:7922789.

Greene, D.A., Naughton, G.A., Briody, J.N., Kemp, A., Woodhead, H., and Corrigan, L. 2005. Bone strength index in adolescent girls: does physical activity make a difference? Br. J. Sports Med. 39: 622-627. doi:10.1136/bjsm.2004.014498. PMID:16118299. PMCID:PMC1725312.

Guenther, P.M., Kott, P.S., and Carriquiry, A.L. 1997. Development of an approach for estimating usual nutrient intake distributions at the population level. J. Nutr. 127: 1106-1112.

PMID:9187624.

Harrison, G.G., Galal, O.M., Ibrahim, N., Khorshid, A., Stormer, A., Leslie, J., and Taha Saleh, N. 2000. Underreporting of food intake by dietary recall is not universal: A comparison of data from Egyptian and American women. J. Nutr. 130: 2049-2054. PMID:10917924.

Herrmann, D., Buck, C., Sioen, I., Kouride, Y., Marild, S., Molnar, D., Mouratidou, T., Pitsiladis, Y., Russo, P., Veidebaum, T., and Ahrens, W. 2015. Impact of physical activity, sedentary behaviour and muscle strength on bone stiffness in 2-10-year-old children-cross-sectional results from the IDEFICS study. Int. J. Behav. Nutr. Phys. Act. 12: 112. doi:10.1186/s12966-015-0273-6. PMID:26377674. PMCID:PMC4574210.

Holmes, B., Ludwa, I.A., Gammage, K.L., Mack, D.E., and Klentrou, P. 2010. Relative importance of body composition, osteoporosis-related behaviors and parental income on bone speed of sound in adolescent females. Osteoporosis Int. 21: 1953-1957. doi:10.1007/s00198-0091152-2. PMID:20094705.

Iuliano-Burns, S., Mirwald, R.L., and Bailey, D.A. 2001. Timing and magnitude of peak height velocity and peak tissue velocities for early, average, and late maturing boys and girls. Am. J. Human Biol. 13: 1-8. doi:10.1002/1520-6300(200101/02)13:1<1::AID-AJHB1000>3.0.CO;2-S. PMID:11466961. 
Janz, K.F., Letuchy, E.M., Burns, T.L., Francis, S.L., and Levy, S.M. 2015. Muscle power predicts adolescent bone strength: Iowa bone development study. Med. Sci. Sports Exerc. 47(10): 2201-2206. doi:10.1249/MSS.0000000000000648. PMID:25751769. PMCID:PMC4549233.

Khosla, S., Melton, L.J. $3^{\text {rd }}$, Dekutoski, M.B., Acheneback, S.J., Oberg, A.L., and Riggs, B.L. 2003. Incidence of childhood distal forearm fractures over 30 years: a population-based study. J. Am. Med. Assoc. 290(11): 1479-1485. doi:10.1001/jama.290.11.1479. PMID:13129988.

Klentrou, P. 2016. Influence of exercise and training on critical stages of bone growth and development. Ped. Exerc. Sci. 28: 178-186. doi:10.1123/pes.2015-0265. PMID:26884506.

Litmanovitz, I., Dolfin, T., Friedland, O., Arnon, S., Regev, R., Shainkin-Kestenbaum, R., Lis, M., and Eliakim, A. 2003. Early physical activity intervention prevents decrease of bone strength in very low birth weight infants. Pediatrics. 112(1): 15-19. PMID:12837861.

Lorbergs, A.L., Farthing, J.P., Baxter-Jones, A.D.G., and Kontulainen, S.A. 2011. Forearm muscle size, strength, force, and power in relation to pQCT-derived bone strength at the radius in adults. Appl Physiol Nutr Metab. 36: 618-625. doi:10.1139/h11-065. PMID:21888527.

Ludwa, I.A., Corbett, L., Yao, M., Gammage, K., Falk, B., and Klentrou, P. 2010. Bone SOS, Bone Turnover and IGF-1 in Adolescent Synchronized Swimmers versus Controls. Ped. Exerc. Sci. 22: 421-430. PMID:20814037.

Macdonald, H., Kontulainen, S., Petit, M., Janseen, P., McKay, H. 2006. Bone strength and its determinants in pre- and early pubertal boys and girls. Bone. 39: 598-608. doi:10.1016/j.bone.2006.02.057. PMID:16600704.

Malina, R.M., Bouchard, C., and Bar-Or, O. 2004. Growth, maturation, and physical activity. Human Kinetics, Champaign, Ill.

Margonato, V., Roi, G.S., Cerizza, C., and Galdabino, G.L. 1994. Maximal isometric force and muscle cross-sectional area of the forearm in fencers. J. Sports Sci. 12: 567-572. doi:10.1080/02640419408732207. PMID:7853453.

Mirwald, R.L., Baxter-Jones, A.D., Bailey, D.A., Beunen, G.P. 2002. An assessment of maturity from anthropometric measures. Med. Sci. Sports Exerc. 34(4): 689-94. PMID:11932580.

Moore, M., Braid, S., Falk, B., and Klentrou, P. 2007. Daily calcium intake in male children and adolescents obtained from the rapid assessment method and the 24-hour recall method. Nutr. J. 6: 24. doi:10.1186/1475-2891-6-24. PMID:17880700. PMCID:PMC2075497.

Nguyen, T.V., Center, J.R., and Eisman, J.A. 2004. Bone mineral density-independent association of quantitative ultrasound measurements and fracture risk in women. Osteoporosis Int. 5: 942947. doi:10.1007/s00198-004-1717-z. PMID:15309384. 
Njeh, C.F., Hans, D., Wu, C., Kantorovich, E., Sister, M., Fuerst, T., and Genant, H.K. 1999. An in vitro investigation of the dependence on sample thickness of the speed of sound along the specimen. Med. Eng. Phys. 21: 651-659. PMID:10699567.

Okumus, M., Okumus, N., Gokoglu, F., Yorgancioglu, Z.R., Tasar, M.A, and Dallar, Y. 2006. The relationship between hand grip strength and hand bone mineral density in children with insulin dependent diabetes mellitus. J. Musculoskel. Res. 10(2): 83-88.

doi:10.1142/S0218957706001741.

Penpraze, V., Reilly, J.J., MacLean, C.M., Montgomery, C., Kelly, L.A., Paton, J.Y., Aitchison, T., and Grant, S. 2006. Monitoring of physical activity in young children: how much is enough? Ped. Exerc. Sci. 18: 483-491. doi:10.1123/pes.18.4.483.

Petit, M.A., Beck, T.J., and Kontulainen, S.A. 2005. Examining the developing bone: what do we measure and how do we do it? J. Musculoskel. Neur. Interact. 5(3): 213-224. PMID:16172512.

Prais, D., Diamond, G., Kattan, A., Salzberg, J., and Inbar, D. 2008. The effect of calcium intake and physical activity on bone quantitative ultrasound measurements in children: a pilot study. J. Bone. Miner. Metab. 26(3):248-253. doi:10.1007/s00774-007-0814-4. PMID:18470665.

Rauch, F., Bailey, D.A., Baxter-Jones, A., Mirwald, R., and Faulkner, R. 2004. The 'muscle-bone' unit during the pubertal growth spurt. Bone 34: 771-775. doi:10.1016/j.bone.2004.01.022. PMID:15121007.

Rauch, F., and Schöenau, E. 2001. The Developing Bone: Slave or Master of Its Cells and Molecules? Pediatr. Res. 50(3): 309-314. doi:10.1203/00006450-200109000-00003.

PMID:11518815.

Sallis, J.F. 2000. Age-related decline in physical activity: a synthesis of human and animal studies. Med. Sci. Sports. Exerc. 32: 1598-1600. PMID:10994911.

Schalamon, J., Singer, G., Schwantzer, G., and Nietosvaara, Y. 2004. Quantitative ultrasound assessment in children with fractures. J. Bone. Miner. Res. 19(8): 1276-1279.

doi:10.1359/JBMR.040401. PMID:15231014.

Schöenau, E. 2005a. From mechanostat theory to development of the "Functional Muscle-BoneUnit". J. Musculoskel. Neur. Interact. 5(3): 232-238. PMID:16172514.

Schöenau, E. 2005b. The "functional muscle-bone unit": a two-step diagnostic algorithm in pediatric bone disease. Pediatr, Nephrol. 30: 356-359. doi:10.1007/s00467-004-1744-1.

PMID:15688231.

Schöenau, E., and Fricke, O. 2008. Mechanical influences on bone development in children. Eur. J. Endocrinol. 159: S27-S31. doi:10.1530/EJE-08-0312. PMID:18787052. 
Schöenau, E., and Frost, H.M. 2002. The "muscle-bone unit" in children and adolescents. Calcif. Tissue Int. 70: 405-407. doi:10.1007/s00223-001-0048-8. PMID:11960207.

Schöenau, E., Neu, C.M., Beck, B., Manz, F., and Rauch, F. 2002. Bone mineral content per muscle cross-sectional area as an index of the functional muscle-bone unit. J. Bone Min. Res. 17(6): 1095-1101. doi:10.1359/jbmr.2002.17.6.1095. PMID:12054165.

Schöenau, E., Neu, C.M., Mokov, E., Wassmer, G., and Manz, F. 2000. Influence of puberty on muscle area and cortical bone area of the forearm in boys and girls. J. Clin. Endocrinol. Metab. 85(3): 1095-1098. doi:10.1210/jcem.85.3.6451. PMID:10720045.

Schöenau, E., Neu, C.M., Rauch, F., and Manz, F. 2001. The development of bone strength at the proximal radius during childhood and adolescence. J. Clin. Endocrinol. Metab. 86(2): 613-618. doi:10.1210/jcem.86.2.7186. PMID:11158018.

Schöenau, E., Neu, C.M., Rauch, F., and Manz, F. 2002. Gender-specific pubertal changes in volumetric cortical bone mineral density at the proximal radius. Bone 31: 110-113.

PMID:12110422.

Schöenau, E., Werhahn, E., Schiedermaier, U., Mokov, E., Schiessl, H., Scheidhauer, K., and Michalk, D. 1996. Influence of muscle strength on bone strength during childhood and adolescence. Horm. Res. 45(suppl 1): 63-66. PMID:8805035.

Sherar, L.B., Esliger, D.W., Baxter-Jones, A.D.G., and Tremblay, M.S. 2007. Age and gender related differences in childhood physical activity: does physical maturity matter? Med. Sci. Sports. Exerc. 39: 830-835. doi:10.1249/mss.0b013e3180335c3c. PMID: 17468582.

Slaughter, M.H., Lohman, T.G., and Boileau, B.A. 1988. Skinfold equations for estimation of body fatness in children and youth. Hum. Biol. 60: 709-723. PMID:3224965.

Tenbrock, K., Kruppa, S., Mokov, E., Querfeld, U., Michalk, D., Schöenau, E. 2000. Analysis of muscle strength and bone structure in children with renal disease. Pediatr. Nephrol. 14: 669-672. PMID:10912540.

Trost, S.G., Kerr, L.M., Ward, D.S, and Pate, R.R. 2001. Physical activity and determinants of physical activity in obese and non-obese children. Int. J. Obes. Relat. Metab. Disord. 25: 822-829. doi:10.1038/sj.ijo.0801621. PMID:11439296.

Trost, S.G., Pate, R.R., Sallis, J.F., Freedson, P.S., Taylor, W.C., Dowda, M., and Sirard, J. 2002. Age and gender differences in objectively measured physical activity in youth. Med. Sci. Sports Exerc. 34(2): 350-355. PMID:11828247.

Turner, C.H., and Robling, A.G. 2004. Exercise as an anabolic stimulus for bone. Curr. Pharm. Des. 10(21): 2629-2641. PMID:15320750. 
Valimaki, M.J., Karkkainen, M., Lamberg-Allardt, C., Laitinen, K., Alhava, E., Heikkinen, J., Impivaara, O., Makela, P., Palmgren, J., Seppanen, R., and Vuori, I. 1994. Exercise, smoking and calcium intake during adolescence and early adulthood as determinants of peak bone mass. $\mathrm{Br}$. Med. J. 309: 230-235. PMID:8069139. PMCID:PMC2540782.

Vicente-Rodríguez, G., Urzanqui, A., Mesana, M.I., Ortega, F.B., Ruiz, J.R., Ezquerra, J., Casajús, J.A., Blay, G., Blay, V.A., Gonzalez-Gross, M., and Moreno, L.A. 2008. AVENAZaragoza Study Group. Physical fitness effect on bone mass is mediated by the independent association between lean mass and bone mass through adolescence: a cross-sectional study. J. Bone Miner. Metab. 26(3): 288-94. doi:10.1007/s00774-007-0818-0. PMID:18470671.

Voide, R., van Lenthe, G.H., and Müller, R. 2008. Differential effects of bone structural and material properties on bone competence in $\mathrm{C} 57 \mathrm{BL} / 6$ and $\mathrm{C} 3 \mathrm{H} / \mathrm{He}$ inbred strains of mice. Calcif. Tissue. Int. 83(1): 61-69. doi:10.1007/s00223-008-9120-y. PMID:18545865.

Wang, Q., Alen, M., Nicholson, P., Suominen, H., Koistinen, A., Kroger, H., and Cheng S. 2007. Weight-bearing, muscle loading and bone mineral accrual in pubertal girls: a 2-year longitudinal study. Bone 40: 1196-1202. doi:10.1016/j.bone.2006.12.054. PMID:17258519.

Wey, H.E., Binkley, T.L., Beare, T.M., Wey, C.L., and Specker, B.L. 2011. Cross-sectional versus longitudinal associations of lean and fat mass with pQCT bone outcomes in children. J. Clin. Endocrinol. Metab. 6(1): 106-114. doi:10.1210/jc.2010-0889. PMID:20926531.

PMCID:PMC3038473.

Yao, M., Ludwa, I., Corbett, L., Klentrou, P., Gammage, K., and Falk, B. 2011. Bone properties of overweight and normal-weight girls and adolescents. Pediatr. Exerc. Sci. 23(1):25-35.

PMID:21467588. 
Table 1. Participant Characteristics.

\begin{tabular}{lccc}
\hline & $\begin{array}{c}\text { Boys } \\
(\mathbf{n = 9 2})\end{array}$ & $\begin{array}{c}\text { Girls } \\
(\mathbf{n = 8 0})\end{array}$ & $\begin{array}{c}\text { Total Group } \\
(\mathbf{n = 1 7 2})\end{array}$ \\
\hline Age (yrs) & $11.7 \pm 2.1$ & $11.7 \pm 1.9$ & $11.7 \pm 2.0$ \\
Maturity Offset (yrs) & $-1.7 \pm 1.7$ & $-0.2 \pm 1.6^{*}$ & $-1.0 \pm 1.8$ \\
Height (cm) & $151.8 \pm 14.8$ & $150.4 \pm 12.4$ & $151.2 \pm 13.8$ \\
Body Mass (kg) & $46.0 \pm 16.0$ & $45.5 \pm 13.4$ & $45.8 \pm 14.8$ \\
Body Fat (\%) & $17.5 \pm 8.5$ & $22.1 \pm 7.6^{*}$ & $19.6 \pm 8.4$ \\
Lean Body Mass (kg) & $37.2 \pm 10.7$ & $34.8 \pm 7.7$ & $36.1 \pm 9.5$ \\
\hline
\end{tabular}

*Significant sex differences $(\mathrm{p}<0.05)$; values represented as mean \pm SD. 
Table 2: Muscle-bone unit variables and modulators in peri-pubertal boys and girls.

\begin{tabular}{|c|c|c|c|}
\hline & $\begin{array}{l}\text { Boys } \\
(n=92)\end{array}$ & $\begin{array}{c}\text { Girls } \\
(\mathbf{n}=\mathbf{8 0})\end{array}$ & $\begin{array}{c}\text { Total Group } \\
(\mathrm{n}=172)\end{array}$ \\
\hline Radial Speed of Sound (m/s) & $3798 \pm 88$ & $3815 \pm 94$ & $3806 \pm 90$ \\
\hline NTx (nM BCE/mM creatinine) & $547 \pm 231$ & $516 \pm 287$ & $532 \pm 259$ \\
\hline Forearm CSA $\left(\mathrm{cm}^{2}\right)$ & $31.6 \pm 8.3$ & $29.1 \pm 6.1^{*}$ & $30.4 \pm 7.4$ \\
\hline Grip Strength (kg) & $23.9 \pm 7.9$ & $21.3 \pm 5.9^{*}$ & $22.7 \pm 7.1$ \\
\hline Grip Strength/CSA $\left(\mathrm{kg} / \mathrm{cm}^{2}\right)$ & $0.75 \pm 0.13$ & $0.73 \pm 0.12$ & $0.74 \pm 0.13$ \\
\hline Total MVH Activity (min/d) & $114 \pm 43$ & $101 \pm 41$ & $108 \pm 42$ \\
\hline Total Energy Intake (kcal/d) & $1696 \pm 500$ & $1492 \pm 354^{*}$ & $1589 \pm 421$ \\
\hline Total Protein Intake (g/d) & $69.5 \pm 23.5$ & $62.0 \pm 18.0^{*}$ & $66.0 \pm 21.4$ \\
\hline Total Calcium Intake (mg/d) & $1015 \pm 442$ & $883 \pm 383^{*}$ & $947 \pm 420$ \\
\hline Total Vitamin D Intake $(\mu \mathrm{g} / \mathrm{d})$ & $4.9 \pm 3.8$ & $4.2 \pm 2.4$ & $4.6 \pm 3.3$ \\
\hline Relative Energy Intake (kcal/kg) & $40.3 \pm 15.2$ & $35.5 \pm 13.4^{*}$ & $37.8 \pm 14.8$ \\
\hline Relative Protein Intake $(\mathrm{g} / \mathrm{kg})$ & $1.63 \pm 0.69$ & $1.48 \pm 0.61$ & $1.56 \pm 0.65$ \\
\hline Relative Calcium (mg/kg) & $24.4 \pm 13.7$ & $21.6 \pm 12.8$ & $23.0 \pm 13.4$ \\
\hline Relative Vitamin D $(\mu \mathrm{g} / \mathrm{kg})$ & $0.12 \pm 0.10$ & $0.10 \pm 0.07$ & $0.11 \pm 0.09$ \\
\hline
\end{tabular}


Table 3. Regression models predicting radial speed of sound (rSOS) using maturity, sex, relative grip strength per cross-sectional area, moderate-to-very hard physical activity (MVH), daily calcium intake and amino-terminal cross-linking propeptide (NTx).

\begin{tabular}{|c|c|c|c|c|}
\hline Variables & Model 1 & Model 2 & Model 3 & Model 4 \\
\hline Maturity Offset (yrs) & $20.5(0.41) \dagger$ & $16.8(0.33) \dagger$ & $15.8(31.2) \dagger$ & $14.2(0.28)^{*}$ \\
\hline Sex & $-33.5(-0.19)^{*}$ & $-25.5(-0.14)$ & $-25.3(-0.14)$ & $-25.0(-0.14)$ \\
\hline Grip Strength/CSA & & $161.1(0.22) \dagger$ & $140.0(0.19)^{*}$ & $134.9(0.18)^{*}$ \\
\hline MVH physical activity (min/day) & & & $-0.30(-0.14)$ & $-0.30(-0.14)$ \\
\hline Calcium Intake (mg/kg) & & & $1.0 \quad(0.15)$ & $1.2(0.17)^{*}$ \\
\hline NTX (nM BCE/mM creatinine) & & & & $-0.1(-0.20)^{*}$ \\
\hline Adjusted $R^{2}$ & $0.12 \dagger$ & $0.16 \dagger$ & $0.18 \dagger$ & $0.21 \dagger$ \\
\hline
\end{tabular}


Figure 1. Adapted model of functional bone development (based on the model proposed by Rauch and Schöenau 2001).

Figure 2. The resulted model of functional bone development (based on the model by Rauch and Schöenau 2001). Dashed arrow represents an indirect effect of behavioural factors on bone properties. Maturity, sex, relative grip strength, physical activity, calcium intake, and NTx together explained a total of $21 \%$ of the variance in radial SOS. 
Challenges with growth, increase in:

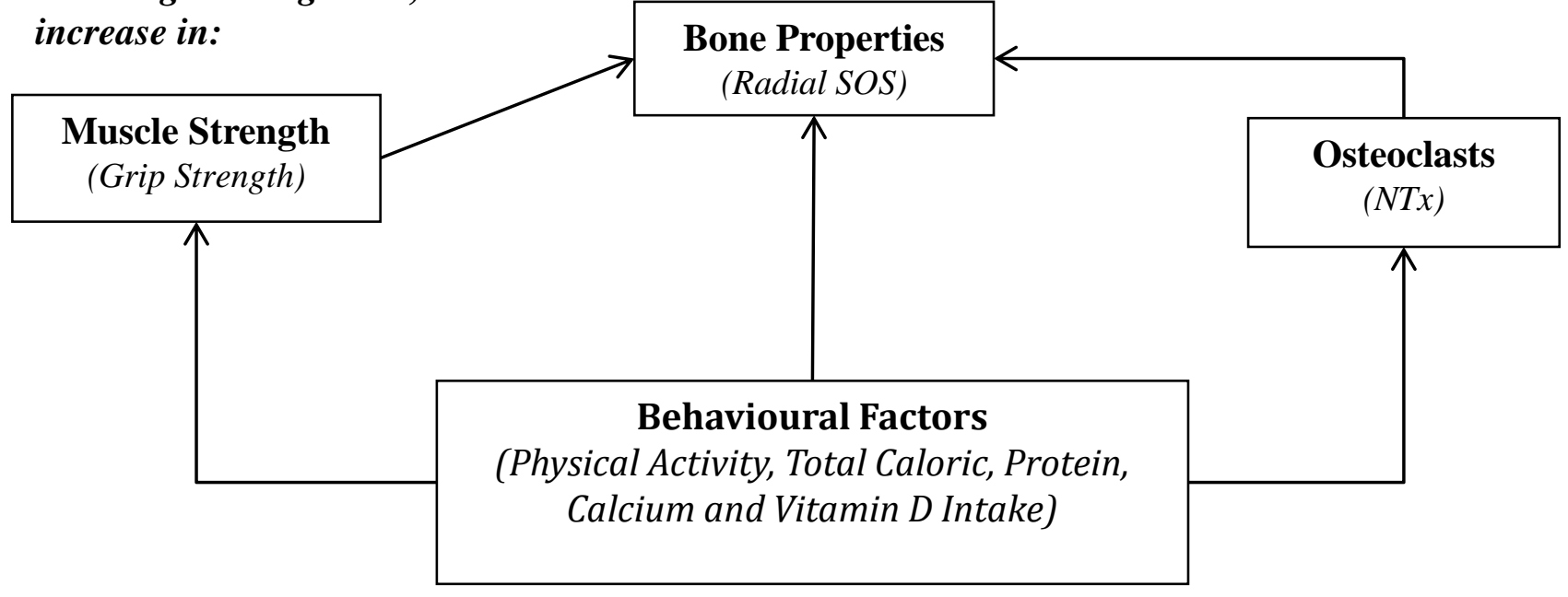




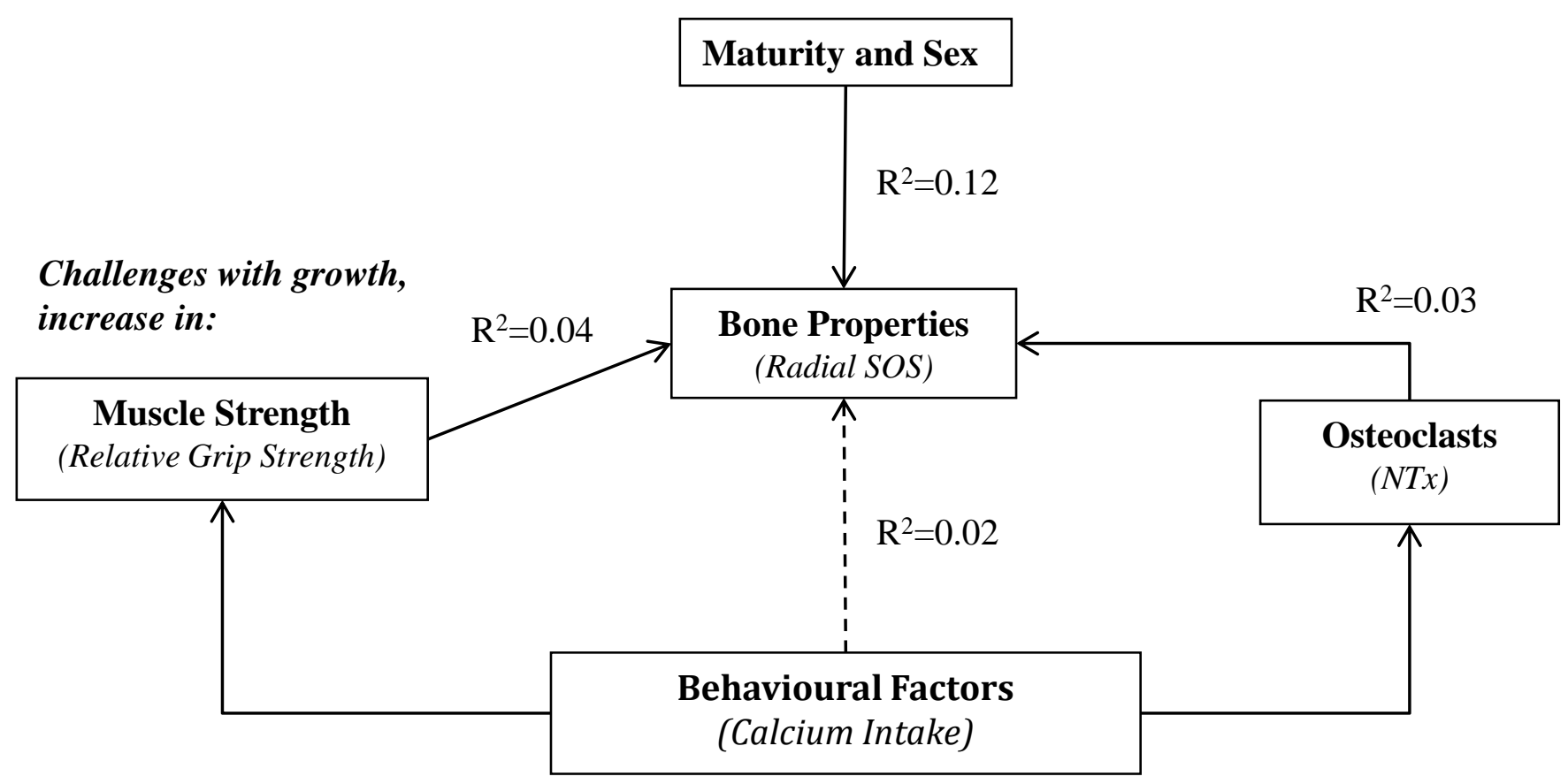

